\title{
Efficacy of High-Flow Oxygen by Nasal Cannula With Active Humidification in a Patient With Acute Respiratory Failure of Neuromuscular Origin
}

\author{
Salvador Díaz-Lobato MD PhD, Miguel Angel Folgado MA MD, \\ Angel Chapa MD, and Sagrario Mayoralas Alises MD PhD
}

\begin{abstract}
The treatment of choice for patients with respiratory failure of neuromuscular origin, especially in patients with hypercapnic respiratory acidosis, is noninvasive ventilation (NIV). Endotracheal intubation and invasive ventilation are indicated for patients with severe respiratory compromise or failure of NIV. In recent years, high-flow oxygen therapy and active humidification devices have been introduced, and emerging evidence suggests that high-flow oxygen may be effective in various clinical settings, such as acute respiratory failure, after cardiac surgery, during sedation and analgesia, in acute heart failure, in hypoxemic respiratory distress, in do-not-intubate patients, in patients with chronic cough and copious secretions, pulmonary fibrosis, or cancer, in critical areas and the emergency department. We report on a patient with amyotrophic lateral sclerosis who arrived at the emergency department with acute hypercapnic respiratory failure. She did not tolerate NIV and refused intubation, but was treated successfully with heated, humidified oxygen via high-flow nasal cannula. Arterial blood analysis after an hour on high-flow nasal cannula showed improved $\mathrm{pH}, \mathrm{P}_{\mathrm{aCO}}$, and awareness. The respiratory acidosis was corrected, and she was discharged after 5 days of hospitalization. Her response to high-flow nasal cannula was similar to that expected with NIV. We discuss the mechanisms of action of heated, humidified high-flow oxygen therapy. Key words: high flow oxygen therapy; noninvasive ventilation; amyotrophic lateral sclerosis; nasal cannula. [Respir Care 2013;58(12):e164-e167. () 2013 Daedalus Enterprises]
\end{abstract}

\section{Introduction}

Noninvasive ventilation (NIV) is the treatment of choice for patients with respiratory failure of neuromuscular origin, especially in patients with hypercapnic respiratory acidosis. ${ }^{1,2}$ Endotracheal intubation is indicated for patients with severe respiratory compromise or NIV failure.

Drs Díaz-Lobato and Mayoralas Alises are affiliated with the Pneumological Department, Ramón y Cajal Hospital, Madrid, Spain. Drs Folgado and Chapa are affiliated with the Emergency Department, Virgen de la Concha Hospital, Zamora, Spain.

The authors have disclosed no conflicts of interest.

Correspondence: Salvador Díaz-Lobato, Pneumological Department, Hospital Universitario Ramón y Cajal, Carretera de Colmenar Viejo, km 9,100, 28034 Madrid, Spain. E-mail: sdiazlobato@gmail.com.

DOI: $10 / 4187 /$ respcare. 02115
In patients with amyotrophic lateral sclerosis (ALS), respiratory muscle weakness is the major cause of mortality, so NIV is an important part of ALS management. ${ }^{3}$ Randomized controlled trials have indicated that therapy with long-term NIV improves survival in ALS patients. It can also improve patient symptoms and health-related quality of life. ${ }^{4}$ NIV has been shown to be effective in correcting respiratory failure, probably by acting to a greater or lesser extent on muscle fatigue, the mechanical properties of the respiratory apparatus, the control of ventilation, the alterations in gas exchange during the night, leading to loss of sensitivity of central and peripheral chemoreceptors, and the degree of dysfunction of the upper airways. ${ }^{5}$

In recent years, heated, humidified high-flow nasal cannula (HFNC) has been introduced into medical practice. ${ }^{6}$ There is emerging evidence that HFNC may be effective in various clinical settings, including acute respiratory failure, ${ }^{7-9}$ after cardiac surgery, ${ }^{10,11}$ during sedation and analgesia, ${ }^{12}$ in acute heart failure, ${ }^{13}$ in hypoxemic respiratory 

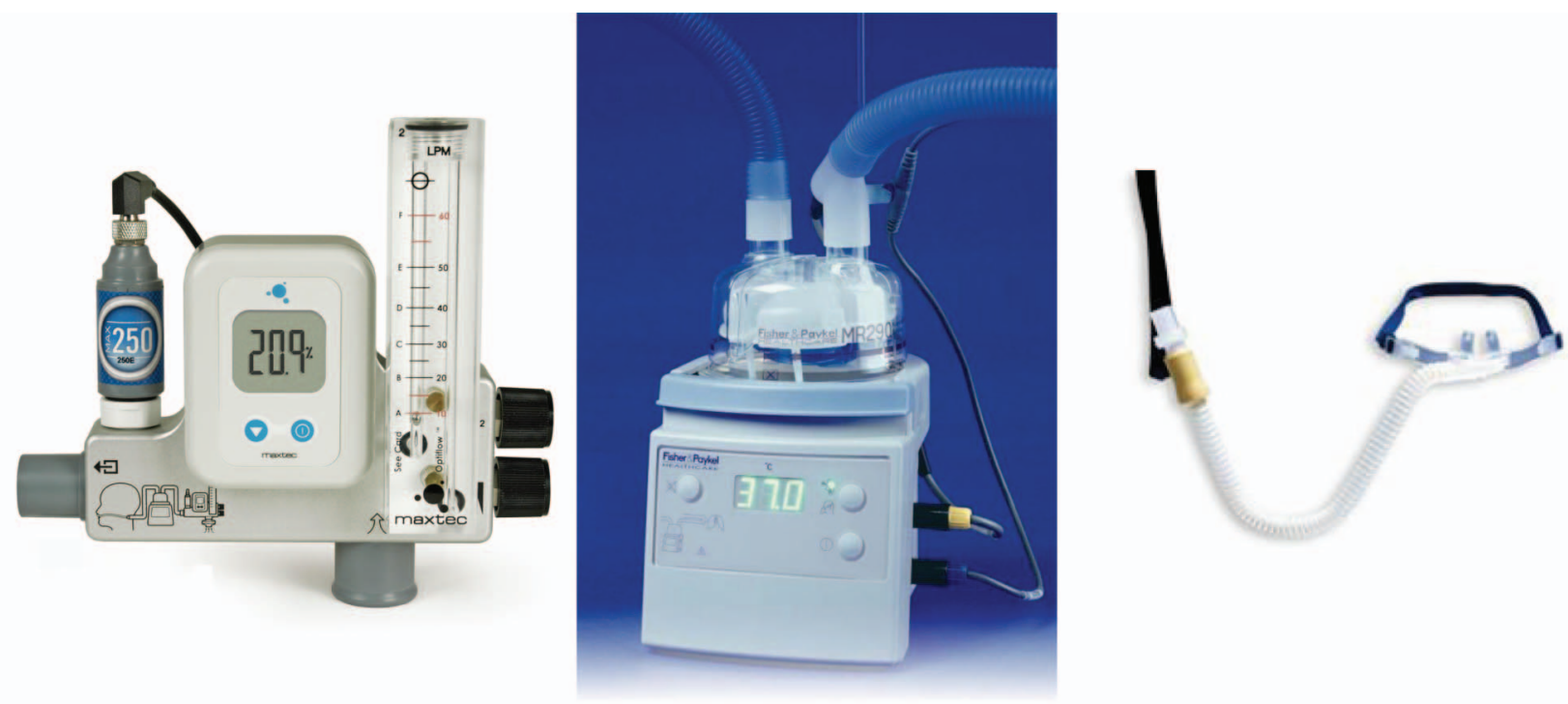

Figure. Left: MaxVenturi flow source. Middle: MR850 humidifier. Right: Optiflow nasal cannula.

distress, in do-not-intubate patients, ${ }^{14}$ and in patients with chronic cough and copious secretions, ${ }^{15}$ pulmonary fibrosis, ${ }^{16}$ or cancer, ${ }^{17}$ in critical care areas ${ }^{18}$ and in the emergency department. ${ }^{19} \mathrm{We}$ report on a patient with ALS with acute hypercapnic respiratory failure who was successfully treated with HFNC.

\section{Case Report}

A 65 year old woman was diagnosed with ALS 6 months prior to presentation, although she had no other noteworthy medical history. Usually she had no dyspnea, orthopnea, or other respiratory symptoms. Recent spirometry showed FVC $2,450 \mathrm{~mL}$ ( $78 \%$ of predicted), $\mathrm{FEV}_{1}$ $1,420 \mathrm{~mL}$ ( $75 \%$ of predicted), and $\mathrm{FEV}_{1} / \mathrm{FVC} 0.7$. Her maximum inspiratory and expiratory pressures were normal: $>80 \mathrm{~cm} \mathrm{H}_{2} \mathrm{O}$. She arrived at the hospital emergency department complaining of progressive dyspnea and decreased level of consciousness over 2 days. She had no fever, cough, or expectoration.

On physical examination she was drowsy, had a blood pressure of $140 / 70 \mathrm{~mm} \mathrm{Hg}$, a heart rate of 110 beats/min, a breathing frequency of 13 breaths/min, a temperature of $36.8^{\circ} \mathrm{C}$, and showing an overall reduction of breath sounds on auscultation. The remaining physical examination was unremarkable. Laboratory tests showed hemoglobin $16 \mathrm{~g} /$ $\mathrm{dL}$, hematocrit $50.6 \%$, white blood cell count $8.7 \times 10^{3}$ cells $/ \mathrm{mL}, 87 \%$ neutrophils, international normalized ratio 0.9 , creatinine $0.59 \mathrm{mg} / \mathrm{dL}$. Arterial blood gas (ABG) analysis of a sample collected while she was on $\mathrm{F}_{\mathrm{IO}_{2}} 0.50$ via air-entrainment mask showed $\mathrm{pH} 7.27, \mathrm{P}_{\mathrm{CO}_{2}} 90 \mathrm{~mm} \mathrm{Hg}$, $\mathrm{P}_{\mathrm{O}_{2}} 88 \mathrm{~mm} \mathrm{Hg}$, and $\mathrm{HCO}_{3}{ }^{-} 40 \mathrm{mmol} / \mathrm{L}$.
Chest radiography showed left costophrenic angle obliteration but no other findings of interest. Her husband related the onset of symptoms with a catarrhal process. The diagnosis was hypercapnic respiratory acidosis, without infiltrates, secondary to a respiratory infection in a patient with ALS.

She was treated with antibiotics and steroids, and started on NIV (Trilogy 100, Philips Respironics, Murrysville, Pennsylvania) via oronasal mask with a passive circuit, in the $\mathrm{S} / \mathrm{T}$ mode, with inspiratory pressure of $16 \mathrm{~cm} \mathrm{H}_{2} \mathrm{O}$, expiratory pressure of $6 \mathrm{~cm} \mathrm{H}_{2} \mathrm{O}$, backup rate of 15 breaths/ min, trigger sensitivity setting 2 , and rise time setting 2 . Oxygen was added at $5 \mathrm{~L} / \mathrm{min}$, and arterial saturation and heart rate were monitored. She had immediate severe intolerance of NIV, with agitation and refusal to continue wearing the mask, so NIV was withdrawn after only $5 \mathrm{~min}$. Arterial oxygen saturation was $80 \%$.

She refused intubation, so we tried heated, humidified HFNC (Optiflow cannula with humidification by an MR880 heated humidifier, both from Fisher \& Paykel Healthcare, Auckland, New Zealand) (Figure), at $45 \mathrm{~L} / \mathrm{min}$ and an $\mathrm{F}_{\mathrm{IO}_{2}}$ of 0.26 . After an hour of HFNC she showed clinical improvement and was more awake. $\mathrm{ABG}$ showed $\mathrm{pH} 7.31, \mathrm{P}_{\mathrm{CO}_{2}} 74 \mathrm{~mm} \mathrm{Hg}, \mathrm{P}_{\mathrm{O}_{2}} 51 \mathrm{~mm} \mathrm{Hg}, \mathrm{HCO}_{3}{ }^{-}$ $36 \mathrm{mmol} / \mathrm{L}$. She was admitted to the respiratory ward. Three hours later, an $\mathrm{ABG}$ showed $\mathrm{pH} 7.40, \mathrm{P}_{\mathrm{CO}_{2}} 61 \mathrm{~mm} \mathrm{Hg}$, $\mathrm{P}_{\mathrm{O}_{2}} 62 \mathrm{~mm} \mathrm{Hg}$, and $\mathrm{HCO}_{3}{ }^{-} 41 \mathrm{mmol} / \mathrm{L}$. She gradually improved, and was discharged after 5 hospital days. HFNC was used throughout her hospitalization. A later chest radiograph showed similar left costophrenic angle obliteration, but no other findings of interest. On the day of discharge, we put the patient on conventional oxygen therapy via nasal prongs, at $1.5 \mathrm{~L} / \mathrm{min}$, for 5 hours in the morning. 


\section{High-Flow Oxygen and Active Humidification in Neuromuscular Acute Respiratory Failure}

An ABG showed pH 7,39, $\mathrm{P}_{\mathrm{CO}_{2}} 48 \mathrm{~mm} \mathrm{Hg}, \mathrm{P}_{\mathrm{O}_{2}} 68 \mathrm{~mm} \mathrm{Hg}$, and $\mathrm{HCO}_{3}{ }^{-} 35 \mathrm{mmol} / \mathrm{L}$. Domiciliary oxygen via nasal prongs, at $1.5 \mathrm{~L} / \mathrm{min}$, was recommended.

\section{Discussion}

In our patient, management was similar to that of a patient with a COPD exacerbation and respiratory hypercapnic acidosis; we used a low $\mathrm{F}_{\mathrm{IO}_{2}}$, aimed to maintain arterial saturation slightly higher than $90 \%$, to prevent greater hypoventilation. We monitored the patient as if she were receiving NIV, and ABG after the first hour of HFNC showed improved $\mathrm{pH}, \mathrm{P}_{\mathrm{aCO}_{2}}$, and awareness. Respiratory acidosis was corrected and the patient was discharged after 5 days of hospitalization. The response to HFNC was similar to that expected with NIV. Basically, we applied the same treatments we use for COPD exacerbation.

Heated, humidified HFNC oxygen can deliver $\mathrm{F}_{\mathrm{IO}_{2}}$ up to 1.0 , at a maximum flow of $60 \mathrm{~L} / \mathrm{min}$, via nasal prongs or cannula. The benefits of HFNC are related to a number of physiological properties. ${ }^{20}$ One of the main effects of high flows in the nasopharynx is to wash $\mathrm{CO}_{2}$, which reduces $\mathrm{CO}_{2}$ rebreathing and provides a reservoir of fresh gas, which reduces dead space and increases the ratio of alveolar ventilation to minute ventilation. ${ }^{21}$ Because HFNC can generate flows that match or exceed a patient's peak inspiratory demand, it is thought that HFNC minimizes the nasopharyngeal resistance, thus decreasing resistive work of breathing. In the same line of reasoning, several authors speculate that the high flow generates a small amount of positive airway pressure 22-24: approximately $1 \mathrm{~cm} \mathrm{H}_{2} \mathrm{O}$ of pressure for every $10 \mathrm{~L} / \mathrm{min}$ of flow. HFNC cannot be considered a CPAP device, but we cannot forget this feature, which provides some benefit to respiratory mechanics. On the other hand, Corley et $\mathrm{al}^{25}$ demonstrated in patients with acute respiratory failure that at least part of the improvement in oxygenation is due to alveolar recruitment. Finally, HFNC is well tolerated because the gas is heated and humidified, HFNC uses nasal prongs instead of face mask, HFNC reduces the work of breathing, and HFNC may help correct hypoxemia. ${ }^{26}$

HFNC's usefulness in critically ill patients, weaning, and as an alternative to intubation is being investigated, and there is promising evidence in the literature. ${ }^{27,28}$ The dead-space wash-out, nasopharyngeal resistance reduction, positive pharyngeal pressure, alveolar recruitment, oxygen dilution reduction, decreased work of breathing, and patient comfort may explain the clinical and gasometric improvement in our patient.

Our experience opens up a field of research in which some patients with acute respiratory failure and hypercapnic acidosis might be treatable with humidified HFNC, as an alternative to conventional NIV. The simplicity of the technique, the lower cost of equipment, and the greater patient tolerance add benefit to the clinical efficacy, which is very important in an era when efficiency should be prioritized. Future research is necessary to clarify these issues.

\section{REFERENCES}

1. Ambrosino N, Carpenè N, Gherardi M. Chronic respiratory care for neuromuscular diseases in adults. Eur Respir J 2009;34(2):444451.

2. Consensus conference. Clinical indications for noninvasive positive pressure ventilation in chronic respiratory failure due to restrictive lung disease, COPD, and nocturnal hypoventilation: a consensus conference report. Chest 1999;116(2):521-534.

3. Vitacca M, Vianello A; Scientific Group on Respiratory Intensive Care of the Italian Association of Hospital Pulmonologists. Respiratory outcomes of patients with ALS: an Italian nationwide survey. Respir Care 2013;58(9):1433-1441.

4. Bourke SC, Bullock RE, Williams TL, Shaw PJ, Gibson GJ. Noninvasive ventilation in ALS: indications and effect on quality of life. Neurology 2003;61(2):171-177.

5. Díaz-Lobato S, Ruiz-Cobos A, García Río FJ, Villamor-León J. Physiopathology of respiratory insufficiency of neuromuscular origin. Rev Neurol 2001;32(1):91-95.

6. Roca O, Riera J, Torres F, Masclans JR. High-flow oxygen therapy in acute respiratory failure. Respir Care 2010;55(4):408-413.

7. Parke RL, McGuinness SP, Eccleston ML. A preliminary randomized controlled trial to assess effectiveness of nasal high-flow oxygen in intensive care patients. Respir Care 2011;56(3):265-270.

8. Sztrymf B, Messika J, Mayot T, Lenglet H, Dreyfuss D, Ricard JD. Impact of high-flow nasal cannula oxygen therapy on intensive care unit patients with acute respiratory failure: a prospective observational study. J Crit Care 2012;27(3):324.

9. Sztrymf B, Messika J, Bertrand F, Hurel D, Leon R, Dreyfuss D, Ricard JD. Beneficial effects of humidified high flow nasal oxygen in critical care patients: a prospective pilot study. Intensive Care Med 2011;37(11):1780-1786.

10. Parke RL, McGuinness SP, Dixon R, Jull A. Protocol for a randomised controlled trial of nasal high flow oxygen therapy compared to standard care in patients following cardiac surgery: the HOT-AS study. Int J Nurs Stud 2012;49(3):338-344.

11. Nicolet J, Poulard F, Baneton D, Rigal JC, Blanloeil Y. High-flow nasal oxygen for severe hypoxemia after cardiac surgery. Ann Fr Anesth Reanim 2011;30(4):331-334.

12. Deitch K, Chudnofsky CR, Dominici P, Latta D, Salamanca Y. The utility of high-flow oxygen during emergency department procedural sedation and analgesia with propofol: a randomized, controlled trial. Ann Emerg Med 2011;58(4):360-364.

13. Carratalá Perales JM, Llorens P, Brouzet B, Albert Jiménez AR, Fernández-Cañadas JM, Carbajosa Dalmau J, et al. High-flow therapy via nasal cannula in acute heart failure. Rev Esp Cardiol 2011; 64(8):723-725.

14. Peters SG, Holets SR, Gay PC. Nasal high flow oxygen therapy in do-not-intubate patients with hypoxemic respiratory distress. Respir Care 2013;58(4):597-600.

15. Díaz Lobato S, Mayoralas Alises S. Effectiveness of high-flow oxygen therapy with warm humidification in a COPD patient with chronic cough. Arch Bronconeumol 2011;47(8):420-421.

16. Boyer A, Vargas F, Delacre M, Saint-Léger M, Clouzeau B, Hilbert G, Gruson D. Prognostic impact of high-flow nasal cannula oxygen supply in an ICU patient with pulmonary fibrosis complicated by acute respiratory failure. Intensive Care Med 2011;37(3):558-559.

17. Epstein AS, Hartridge-Lambert SK, Ramaker JS, Voigt LP, Portlock CS. Humidified high-flow nasal oxygen utilization in patients with 


\section{High-Flow Oxygen and Active Humidification in Neuromuscular Acute Respiratory Failure}

cancer at Memorial Sloan-Kettering Cancer Center. J Palliat Med 2011;14(7):835-839.

18. Wattier BA, Ward JJ. High-flow nasal cannula oxygen in critically ill adults: do the nose or lungs know there's a difference? Respir Care 2011;56(3):355-358.

19. Lenglet H, Sztrymf B, Leroy C, Brun P, Dreyfuss D, Ricard JD. Humidified high flow nasal oxygen during respiratory failure in the emergency department: feasibility and efficacy. Respir Care 2012; 57(11):1873-1878.

20. Ricard JD. High flow nasal oxygen in acute respiratory failure. Minerva Anestesiol 2012;78(7):836-841.

21. Dysart K, Miller T, Wolfson MR, Shaffer TH. Research in high flow therapy: mechanisms of action. Respir Med 2009;103(10):14001405.

22. Parke RL, Eccleston ML, McGuinness SP. The effects of flow on airway pressure during nasal high-flow oxygen therapy. Respir Care 2011;56(8):1151-1155

23. Ritchie JE, Williams AB, Gerard C, Hockey H. Evaluation of a humidified nasal high-flow oxygen system, using oxygraphy, capnography and measurement of upper airway pressures. Anaesth Intensive Care 2011;39(6):1103-1110.

24. Urbano J, del Castillo J, López-Herce J, Gallardo JA, Solana MJ, Carrillo Á. High-flow oxygen therapy: pressure analysis in a pediatric airway model. Respir Care 2012;57(5):721-726.

25. Corley A, Caruana LR, Barnett AG, Tronstad O, Fraser JF. Oxygen delivery through high-flow nasal cannulae increase end-expiratory lung volume and reduce respiratory rate in post-cardiac surgical patients. Br J Anaesth 2011;107(6):998-1004.

26. Cuquemelle E, Pham T, Papon JF, Louis B, Danin PE, Brochard L. Heated and humidified high-flow oxygen therapy reduces discomfort during hypoxemic respiratory failure. Respir Care 2012;57(10): 1571-1577.

27. Ward JJ. High-flow oxygen administration by nasal cannula for adult and perinatal patients. Respir Care 2013;58(1):98-122.

28. El-Khatyb MF. High-flow nasal cannula oxygen therapy during hypoxemic respiratory failure. Respir Care 2012;57(10):1696-1698. 